\title{
Molecular simulations of adsorption isotherms of small alkanes in FER-, TON-, MTW- and DON-type zeolites
}

\author{
Jean-Marie B. Ndjaka ${ }^{a}$, Gooitzen Zwanenburg ${ }^{b}$, Berend Smit ${ }^{b}$, Merijn Schenk ${ }^{b, *}$ \\ ${ }^{a}$ Department of Physics, University of Yaounde I, P.O. Box 812, Yaounde, Cameroon \\ ${ }^{\mathrm{b}}$ Department of Chemical Engineering, University of Amsterdam, Nieuwe Achtergracht 166, 1018 WV Amsterdam, The Netherlands
}

Received 6 August 2003; received in revised form 4 December 2003; accepted 6 December 2003

\begin{abstract}
Computer simulations are a useful tool in the study of the adsorption of alkanes in zeolites, provided the zeolite-alkane interactions are described in an adequate manner. MFI-type zeolites are among the most frequently studied types of zeolite. Consequently, zeolite specific force fields are often parameterized using experimental data obtained on MFI-type zeolites. In this paper we examine whether these force fields can be used to simulate adsorption in other zeolite types. We find that experimentally obtained isotherms of small alkanes on high silica FER-, TON-, MTW-, and DON-type zeolites can be accurately modeled using a single force field.
\end{abstract}

(C) 2003 Elsevier Inc. All rights reserved.

Keywords: Zeolites; Adsorption; Alkanes; Molecular modeling

\section{Introduction}

Zeolites find many applications in the petrochemical industries because of their ability to separate and catalytically convert hydrocarbon feedstocks. Important in our understanding of the processes involved in these applications is our knowledge of the adsorption behavior of hydrocarbons in zeolitic pores [1-9]. This adsorption behavior is usually quantified by means of the adsorption isotherm, which represents the amount of hydrocarbon adsorbed in a pressure range at a given temperature. Experimentally, the determination of adsorption isotherms can be quite time consuming because of the slow diffusion of long-chain hydrocarbons in the pores of a zeolite [10]. Molecular simulation can provide a cost-effective way of determining adsorption isotherms [8,9,11-19], especially under conditions not readily amenable to experiments (high pressures and temperatures). Another advantage of performing simulations is the inherent capability of the programs in providing snapshots of adsorbed molecules. Such detailed information on a molecular level has proven to be of considerable importance to our understanding of the

\footnotetext{
${ }^{*}$ Corresponding author. Tel.: +31-20-525-5265.
}

E-mail address: merijn@science.uva.nl (M. Schenk). driving forces behind the sometimes peculiar shape selective adsorption behavior of hydrocarbon isomers in zeolites [8,9,11-13].

To compute the adsorption properties of the hydrocarbons correctly we need an accurate description of the non-bonded interactions between the methylene groups of the hydrocarbons and the oxygen atoms of the zeolite framework. In many studies these interactions are described by a 12-6 Lennard-Jones potential. The size parameter $\sigma$ and the energy parameter $\epsilon$ are fitted so as to accurately reproduce both the Henry coefficient and the heat of adsorption of small alkanes in Silicalite-1 (MFI topology) [11]. In Ref. [14] it was shown that an accurate prediction of the adsorption in the Henry regime will also yield an accurate description of the complete adsorption isotherm.

The reason why Silicalite- 1 is used for parameterization is because there are sufficient experimental results available to arrive at a reliable model. Consequently this zeolite has been studied extensively by means of computer simulations [16-23]. Some studies found that the Silicalite-1 parameter set can also satisfactory describe the adsorption properties in other zeolites, but a systematic study whether this parameter set can also correctly describe complete isotherms over a wide range of pore sizes is lacking. In this paper we will compare our 
simulation results to experimentally obtained adsorption isotherms of small alkanes in a set of high silica zeolites with a wide range of pore sizes.

\section{Simulation technique}

Zeolites are microporous crystalline materials, with pores of about the same size as small alkanes. The structures are build up from $\mathrm{TO}_{4}$ tetrahedral units, were the central $\mathrm{T}$ atom is usually $\mathrm{Si}$ or $\mathrm{Al}$. In these pores there are often high barriers present for diffusing molecules. For example, Fig. 1 shows the energy landscape of the FER structure. The light grey area's show the 10ring channels and the cages. Both are connected to each other via a narrow 8-ring window. Because of diffusional barriers like these, the computational method of choice to obtain equilibrium properties like adsorption isotherms is the Monte Carlo method.

For the calculation of the heats of adsorption and the Henry coefficient we perform Monte Carlo simulations in the $N V T$ ensemble at infinite dilution (i.e. using a single particle). During such a simulation, trial moves are performed to insert an alkane at a random position inside the zeolite. We use the configurational-bias Monte Carlo technique to increase the acceptance ratio of these insertions [24]. Additionally trial moves are performed to translate, rotate and partial-regrow a molecule at its place of insertion. For the calculation of adsorption isotherms we perform Monte Carlo simulations in the grand-canonical $(\mu V T)$ ensemble. In this ensemble, additional trial moves are performed to exchange molecules between a zeolite and a molecule reservoir of constant chemical potential.

The alkanes are described with a united-atom model, i.e. $\mathrm{CH}_{3}$ and $\mathrm{CH}_{2}$ groups are considered as single

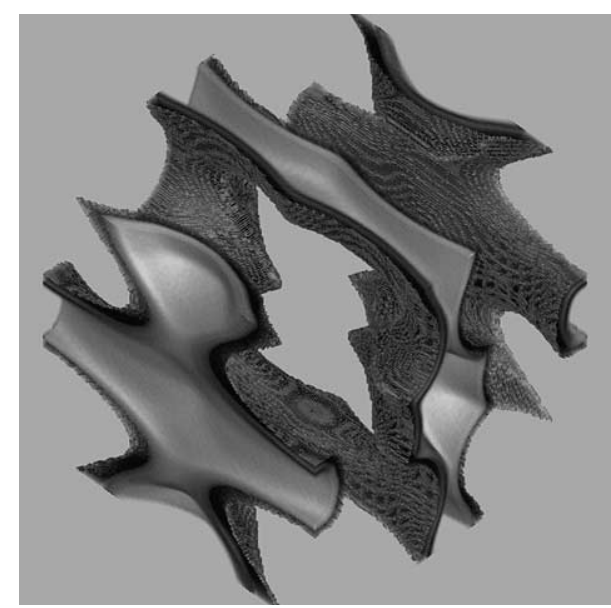

Fig. 1. The energy landscape inside the FER structure as 'felt' by a diffusing methane molecule. The area's in light grey are the 10-ring channels and the small cages. The dark grey areas are the zeolite walls. (picture by D. Dubbeldam).
Table 1

Pore dimensions of zeolites [34]

\begin{tabular}{llll}
\hline Zeolite & Topology & Oxygens in ring & Pore dimensions/A \\
\hline FER & 2-D & 10,8 & $5.4 \times 4.2,4.8 \times 3.5$ \\
TON & 1-D & 10 & $5.7 \times 4.6$ \\
MFI & 2-D & 10,10 & $5.6 \times 5.3,5.5 \times 5.1$ \\
MTW & $1-D$ & 12 & $6.0 \times 5.6$ \\
DON & 1-D & 14 & $8.2 \times 8.1$ \\
\hline
\end{tabular}

interaction centers. The bond length between the atoms is kept fixed. The bond-bending is described by a harmonic potential, and the non-bonded interactions are modeled using Lennard-Jones potentials taken from Ref. [25]. The zeolite is modeled as a rigid crystal [26], consisting exclusively of $\mathrm{SiO}_{2}$, so as to make the calculation of the zeolite-alkane interactions efficient. Dispersive interactions with the oxygen atoms of the silica framework are assumed to dominate the zeolite-alkane interactions. These interactions are also described by Lennard-Jones potentials. The potentials have been fitted to the adsorption enthalpies and Henry coefficients of linear and mono-branched alkanes in Silicalite-1. More details about the simulation method and the force fields have been reported elsewhere [11]. We have taken the crystal structures of the zeolites from the Cerius ${ }^{2}$ [27] package (Table 1).

\section{Results and discussion}

Thermodynamics: We examined the adsorption behavior of methane, ethane and propane in the zeolites FER, TON, MFI, MTW, and DON using the Lennard-Jones parameter set proposed by Vlugt et al. [11]. The results of the simulations at infinite dilution are given in Tables 2 and 3 , the results for the adsorption isotherms are given in Figs. 2-4. In both cases the results are compared to experiments by Savitz et al. [28], Eder and Lercher [29] and Hampson and Rees [30].

As stated before, it is crucial to be able to reproduce both the Henry coefficient and the heat of adsorption (at infinite dilution) in order to correctly calculate adsorption over a range of temperatures. Since the LennardJones parameter set of Vlugt et al. was fitted using data obtained on the zeolite MFI, we also include results for the heat of adsorption and Henry coefficient for this zeolite in Tables 2 and 3.

The experimental results for the widely studied zeolite MFI presented in Table 2 show quite some variation. If we use the scatter of the experimental data for MFI as a measure for the typical experimental uncertainties, we should allow for an uncertainty of $2 \mathrm{~kJ} / \mathrm{mol}$. If we take this uncertainty into account, comparison of the simulation data with the experimental data shows satisfactory agreement for the zeolites MTW, DON, and TON 
Table 2

Zero-coverage isosteric heats of adsorption

\begin{tabular}{|c|c|c|c|c|c|c|c|c|c|}
\hline \multirow[t]{3}{*}{ Zeolite } & \multicolumn{9}{|c|}{$-Q_{\mathrm{st}} / \mathrm{kJ} / \mathrm{mol}$} \\
\hline & \multicolumn{3}{|c|}{$\mathrm{CH}_{4}$} & \multicolumn{3}{|l|}{$\mathrm{C}_{2} \mathrm{H}_{6}$} & \multicolumn{3}{|l|}{$\mathrm{C}_{3} \mathrm{H}_{8}$} \\
\hline & Sim & Exp & Ref. & Sim & Exp & Ref. & $\mathrm{Sim}$ & Exp & Ref. \\
\hline \multirow[t]{2}{*}{ FER } & 21.6 & 27.7 & {$[28]$} & 34.2 & 41.7 & [28] & 43.9 & 53.3 & [28] \\
\hline & & & & & & & & 49 & [29] \\
\hline \multirow[t]{3}{*}{ TON } & 21.0 & 27.2 & [28] & 32.1 & 39.0 & [28] & 42.0 & 48.8 & [28] \\
\hline & & & & & 31.9 & [30] & & 42.0 & [30] \\
\hline & & & & & & & & 49 & [29] \\
\hline \multirow[t]{4}{*}{ MFI } & 20.0 & 20.9 & [28] & 30.4 & 31.1 & [28] & 39.1 & 41.4 & [28] \\
\hline & & 20 & [35] & & 33 & [35] & & 40 & [35] \\
\hline & & 18.6 & [36] & & 30.7 & [36] & & 40.9 & [36] \\
\hline & & & & & 32.8 & [37] & & 39.9 & [37] \\
\hline MTW & 18.8 & 20.9 & [28] & 29.2 & 29.5 & [28] & 38.8 & 37.6 & [28] \\
\hline DON & 13.4 & 14.2 & [28] & 20.1 & 22.2 & [28] & 26.0 & 28.1 & [28] \\
\hline
\end{tabular}

Comparison between this work (sim) and experiments (exp) at $T=298 \mathrm{~K}$

Table 3

Henry's constants

\begin{tabular}{|c|c|c|c|c|c|c|c|}
\hline \multirow[t]{3}{*}{ Zeolite } & \multirow[t]{3}{*}{$T(\mathrm{~K})$} & \multicolumn{6}{|c|}{$K_{\mathrm{H}} / \mathrm{mmol} / \mathrm{g} / \mathrm{Pa}$} \\
\hline & & \multicolumn{2}{|l|}{$\mathrm{CH}_{4}$} & \multicolumn{2}{|l|}{$\mathrm{C}_{2} \mathrm{H}_{6}$} & \multicolumn{2}{|l|}{$\mathrm{C}_{3} \mathrm{H}_{8}$} \\
\hline & & Sim & Exp & Sim & Exp & Sim & Exp \\
\hline FER & 309 & $7.2 \times 10^{-6}$ & $2.0 \times 10^{-5}$ & $1.9 \times 10^{-4}$ & $7.2 \times 10^{-4}$ & $9.1 \times 10^{-4}$ & \\
\hline TON & 298 & $5.4 \times 10^{-6}$ & & $9.2 \times 10^{-5}$ & $9.1 \times 10^{-5}$ & $6.8 \times 10^{-4}$ & $7.0 \times 10^{-4}$ \\
\hline TON & 309 & $4.0 \times 10^{-6}$ & $6.8 \times 10^{-6}$ & $5.8 \times 10^{-5}$ & $1.4 \times 10^{-4}$ & $3.7 \times 10^{-4}$ & \\
\hline MFI & 309 & $8.3 \times 10^{-6}$ & $6.3 \times 10^{-6}$ & $1.6 \times 10^{-4}$ & $1.2 \times 10^{-4}$ & $1.5 \times 10^{-3}$ & \\
\hline MTW & 309 & $3.7 \times 10^{-6}$ & $4.0 \times 10^{-6}$ & $8.8 \times 10^{-5}$ & $9.3 \times 10^{-5}$ & $1.1 \times 10^{-3}$ & \\
\hline DON & 309 & $1.3 \times 10^{-6}$ & $3.2 \times 10^{-6}$ & $1.2 \times 10^{-5}$ & $1.6 \times 10^{-5}$ & $7.9 \times 10^{-5}$ & $1.1 \times 10^{-4}$ \\
\hline
\end{tabular}

Comparison between this work (sim) and experiments (exp) from Ref. [28] at $T=309 \mathrm{~K}$ and Ref. [30] at $T=298 \mathrm{~K}$.
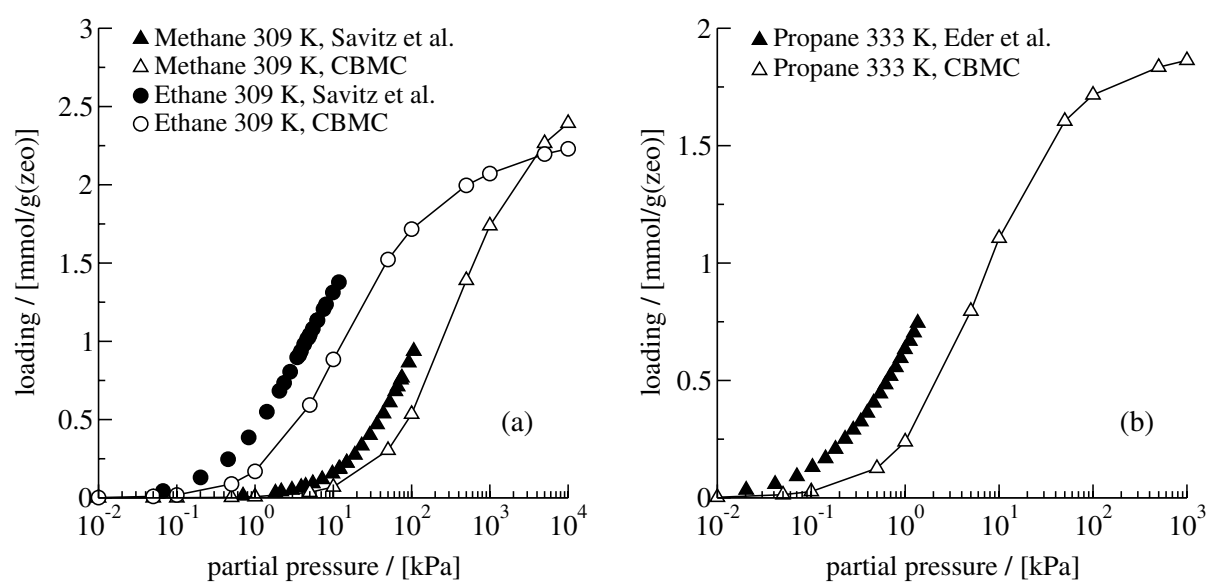

Fig. 2. Adsorption isotherms for methane (a), ethane (a), and propane (b) in FER-type zeolites: CBMC simulations vs experiments from Savitz et al. (a), and Eder et al. (b). The lines serve as a guide to the eye.

of Hampson et al. For FER and TON of Savitz et al. and Eder et al., the agreement is less satisfactory. The results for the Henry coefficient show a similar trend (see Table 3), with one exception: The results for the Henry coefficient for TON are all in quite good agreement with the experimental results. Also the results for the iso- therms show the same trend. The agreement between our simulations and the experiments is in general good for TON, MTW, and DON, and again somewhat less for FER.

We have two possible explanations for why in particular for FER we observe a significant deviation of our 

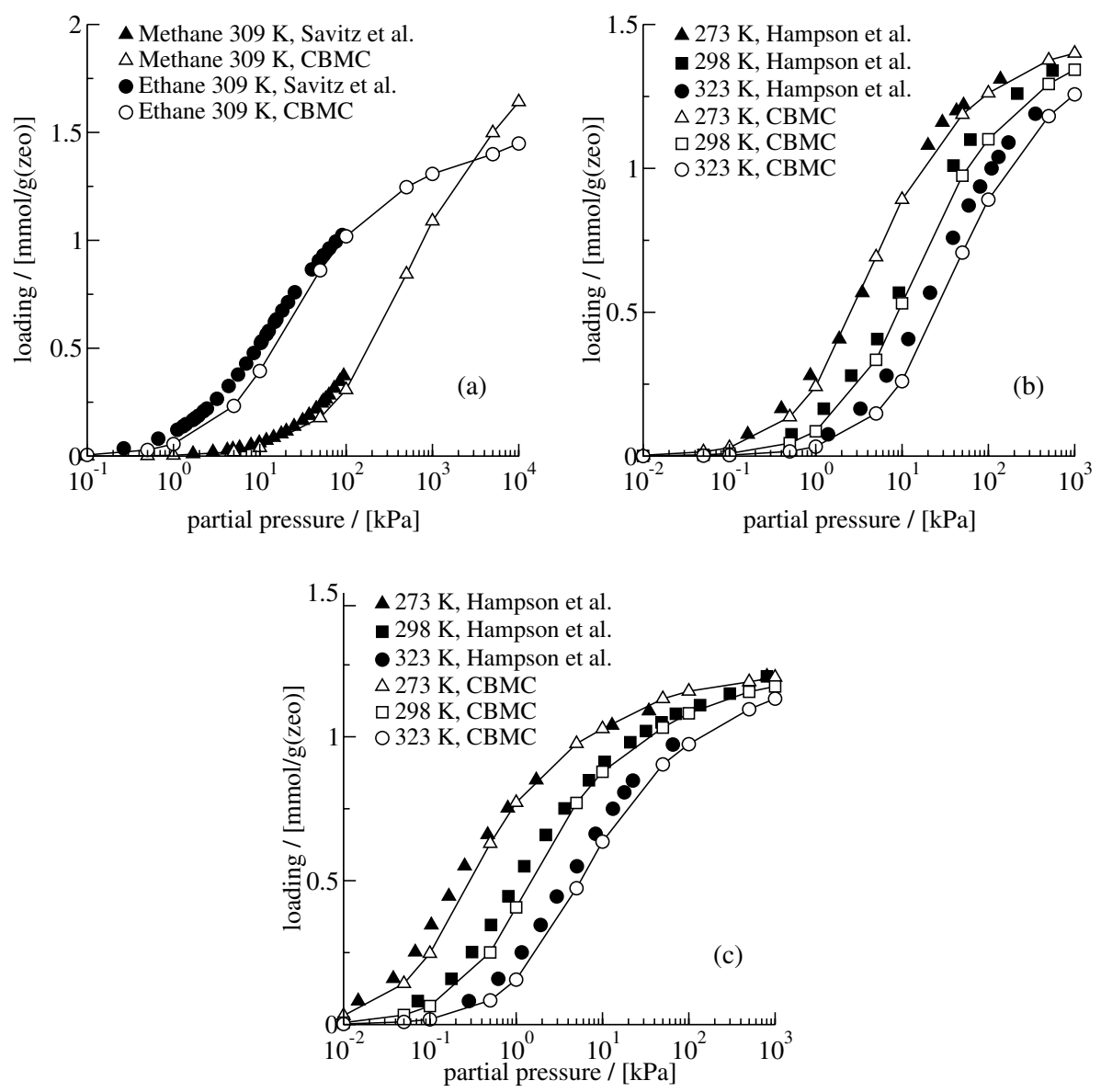

Fig. 3. Adsorption isotherms for methane (a), ethane (a,b), and propane (c) in TON-type zeolites: CBMC simulations vs experiments from Savitz et al. (a), and Hampson et al. (b,c). The lines serve as a guide to the eye.

simulation results from the experimental data. One reason could be the relatively low $\mathrm{Si} / \mathrm{Al}$ ratio of the sample used in the experiments. For each aluminium there is also a hydrogen atom present. It has been shown for H-MFI that these hydrogen atoms can give a negative contribution to the heat of adsorption of up to 10 $\mathrm{kJ} / \mathrm{mol}$ [31]. This will also result in a higher Henry coefficient, and thus in a larger initial slope of the adsorption isotherm. Another reason could be the sensitivity of the Lennard-Jones potential for small changes in the parameters when the oxygen and carbon groups are in close proximity. This effect would be the largest in the case of FER, since this zeolite has the narrowest pore system of all zeolites under evaluation. The parameters fitted on MFI can be less than optimal, resulting in a deviation for FER. Interestingly, other studies found a similar deviation from experimental results using a different forcefield [15].

In the case of TON, both the Henry coefficient and the adsorption isotherms are in good agreement with all the experiments, while the heat of adsorption deviates somewhat from the experimental values of Savitz et al. and Eder et al. Again, this difference could be attributed to the presence of acid sites in the zeolite sample, since the sample used has a Si/Al of 52. Eder and Lercher [29] have shown that such an acid site density in TON leads to an increase of the heat of adsorption of $7 \mathrm{~kJ} / \mathrm{mol}$. This is exactly the difference between our simulations and those experiments. The good aggreement between the simulation results and the results of Hampson et al. further corroborates this explanation, since their sample contains no acid sites. The fact that the Henry coefficients correspond well, despite this deviation in the heat of adsorption, could be attributed to a compensation effect introduced by Eder and Lercher [31]. This effect describes an opposite change in the enthalpy and entropy of adsorption when alkanes are adsorbed on acid sites compared to adsorption into a purely silicious matrix. So when the enthalpy of adsorption is increased due to the interaction between alkanes and the protons, the entropy is decreased due to a decrease in the conformational freedom of the alkanes.

Of course the other possible reason for the deviation in the heat of adsorption is that our model may need some modification. As already mentioned, both the Henry coefficient and the adsorption isotherms are in 

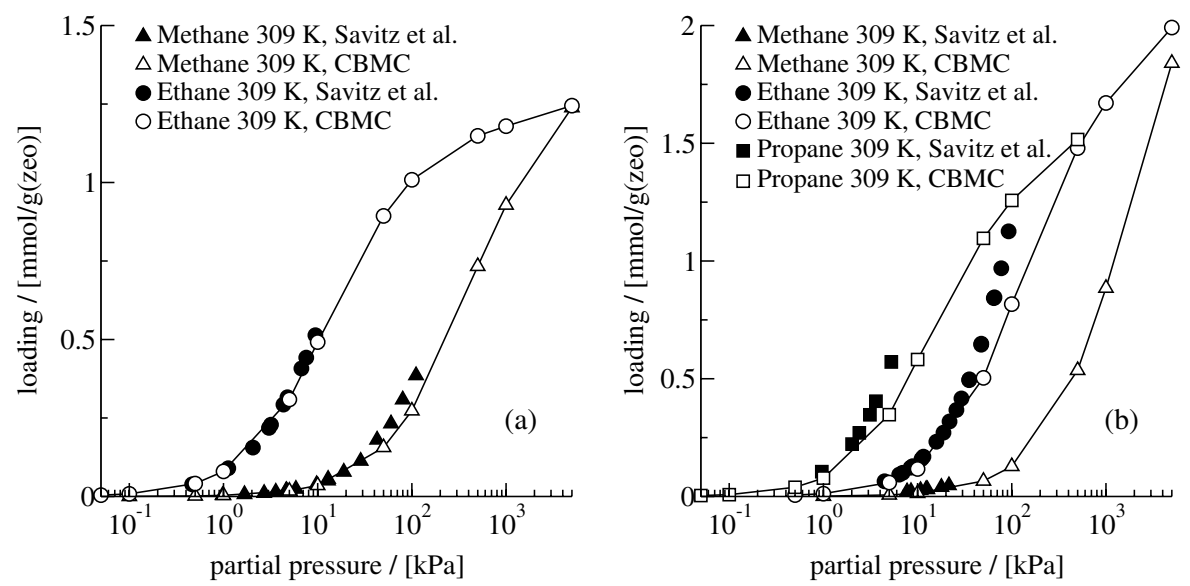

Fig. 4. Adsorption isotherms for methane, ethane, and propane in MTW- (a), and DON-type (b) zeolites: CBMC simulations vs experiments from Savitz et al. The lines serve as a guide to the eye.

good agreement. This implies that, provided that the experimental determination of the heats of adsorption are correct, the model overestimates the entropic contribution to the Henry coefficient. This will be the case when the alkanes are modeled too small, resulting in an underestimation of the excluded volume (the zeolite) and an overestimation of the conformational freedom of the alkanes. The results for FER suggest that the size parameter sigma, if anything, is too big (which will result in an underestimation of the entropic contribution) and not too small. This makes us believe that the most probable reason for the deviation lies in the presence of acid sites in the TON samples of Savitz et al. and Eder et al.

Siting: We examined the preferential adsorption sites of the alkanes in the zeolites. For each zeolite a result is given in the Figs. 5-7 in the form of density distributions. These distributions are constructed by plotting the position of the centers of mass of the molecules in the simulation box at fixed intervals throughout the simulation. The density of the dots is a measure of the probability of finding the center of mass of a particular molecule at a given position.

From these figures we obtain information on the location of the the adsorption sites. Thus, Fig. 5 shows the siting of propane in FER at low and high pressure. It shows that at low loading propane preferentially adsorbs in the small cages, accessible through the 8-ring windows. At high pressure propane adsorbs in both the cages and the 10-ring channels. This observation compares nicely to the results of NMR experiments performed by Van Well et al. [32,33]. Similar results were obtained in the computational part of their study [15,32] using a slightly different forcefield from the one used in this study.

In Fig. 6 the undulations in the channels of TON can be observed as the methane molecules adsorb homogeneously throughout the channels. These undulations

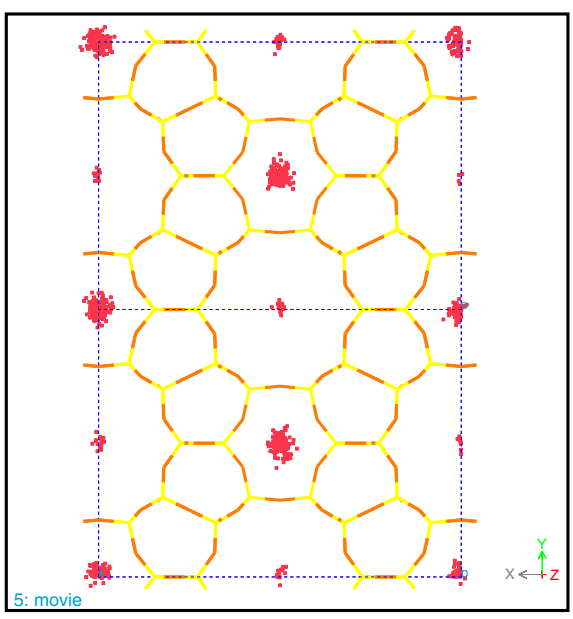

(a) $0 \mathrm{kPa}$

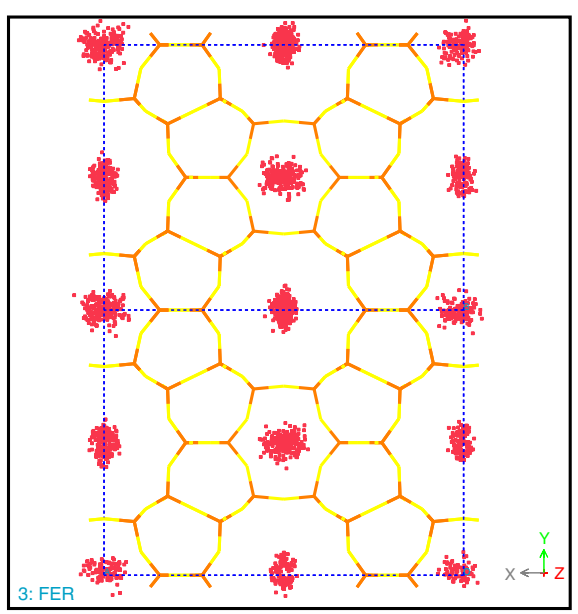

(a) $500 \mathrm{kPa}$

Fig. 5. Density distribution of propane in FER in the Henry regime (a) and at $500 \mathrm{kPa}$ (b) at $T=309 \mathrm{~K}$. 


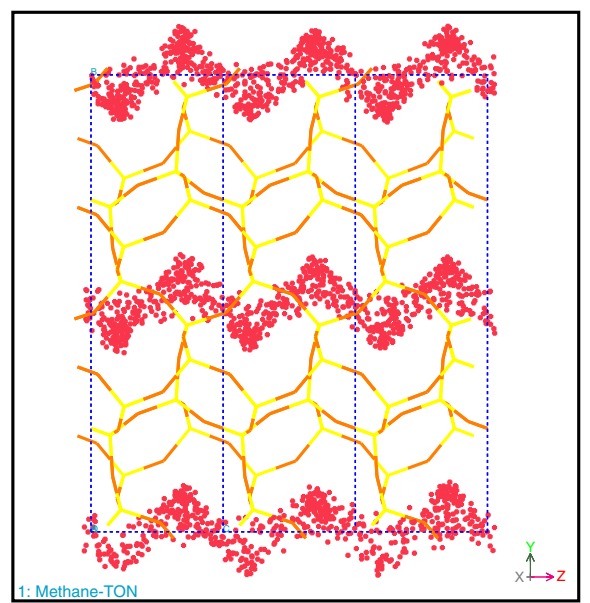

(a) bc plane

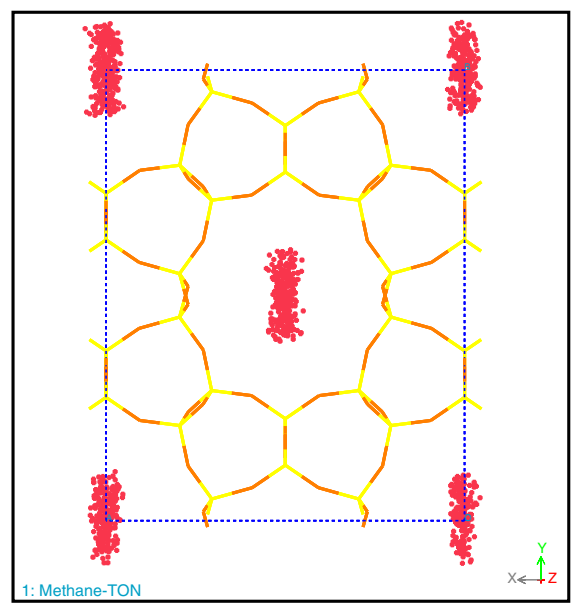

(b) ab plane

Fig. 6. Density distribution of methane in TON at $500 \mathrm{kPa}, T=309 \mathrm{~K}$ projected on the $b c$ plane (a) and the $a b$ plane (b).

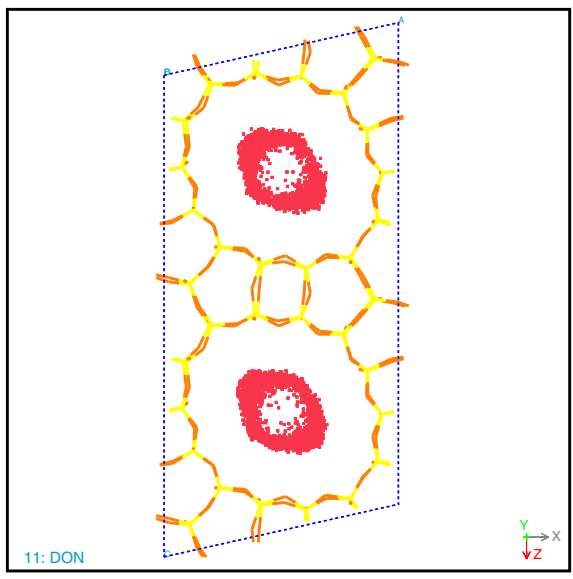

(a) DON

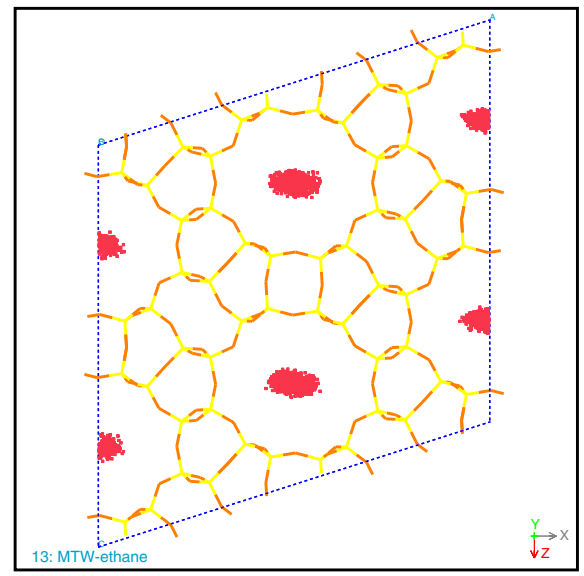

(b) MTW

Fig. 7. Density distribution of ethane in DON (a) and MTW (b) at $500 \mathrm{kPa}, T=309 \mathrm{~K}$.

give rise to incommensurate diffusion of double branched alkanes, which is highly dependent on the spacing between the methyl groups [7].

The difference in pore size between the uni-directional pores of DON and MTW is reflected in the distribution of adsorbed ethane, as shown in Fig. 7. The pore wall of MTW forces the ethane molecules to adsorb at the center of the pore. In DON, the pore is of such a size that the ethane molecules adsorb to the wall, leaving the center of the pore unoccupied. This difference in available space is also reflected in the maximum adsorption capacity of both zeolites.

\section{Conclusions}

We use Monte Carlo simulations to study the adsorption of small alkanes in a series of all-silica zeolites. This series, consisting of FER, TON, MTW and
DON, is of interest because of the wide range of pore sizes in these zeolites. We focus on whether a well known model for the zeolite-alkane interactions, parameterized using experimental data obtained on the zeolite MFI, can be used to calculate these adsorption properties in both low and high pressure regimes. The results obtained from our simulations show that this forcefield can indeed accurately reproduce experimental results from Savitz et al., Eder et al, and Hampson et al. The only significant deviations between experiments and our simulations occur in the zeolite FER, but they are by no means of such an extent that the results become unusable. For example, we have shown that snapshots of adsorbed alkanes produced during these simulations still give an accurate representation of the actual siting of the molecules inside the pore system. Additionally we expect results to show correct trends in a direct comparison of a series of alkanes and their mixtures adsorbed in FER. 


\section{Acknowledgements}

We thank the Stichting Nationale Computer Faciliteiten (National Computer Facilities Foundation) and SARA for the use of their supercomputer facilities. These investigations are supported in part by the Netherlands Research Council for Chemical Sciences (CW) with financial aid from the Netherlands Technology Foundation (STW). We thank Daan Frenkel for making available a NWO-Spinoza travel grant for J.-M.B. Ndjaka, and David Dubbeldam for providing us with a nice representation of the FER structure (Fig. 1).

\section{References}

[1] W.O. Haag, in: J. Weitkamp, H.G. Karge, H. Pfeifer, W. Hölderich (Eds.), Zeolites and Related Microporous Materials: State of the Art 1994, Studies in Surface Science and Catalysis, vol. 84, Elsevier, Amsterdam, 1994, p. 1375.

[2] P.M.M. Blauwhoff, J.W. Gosselink, E.P. Kieffer, S.T. Sie, W.H.J. Stork, in: J. Weitkamp, L. Puppe (Eds.), Catalysis and Zeolites, Springer, Berlin, 1999, p. 437.

[3] R.H. Jensen, in: M. Guisnet, J.-P. Gilson (Eds.), Zeolites for Cleaner Technologies, Imperial College Press, London, 2002, p. 75.

[4] T.F. Degnan, J. Catal. 216 (2003) 32.

[5] C.R. Marcilly, Top. Catal. 13 (2000) 357.

[6] T.L.M. Maesen, M. Schenk, T.J.H. Vlugt, J.P. de Jonge, B. Smit, Br. J. Catal. 188 (1999) 403.

[7] M. Schenk, B. Smit, T.J.H. Vlugt, T.L.M. Maesen, Angew. Chem. Int. Ed. Engl. 40 (2001) 736.

[8] M. Schenk, S. Calero, T.L.M. Maesen, L.L. van Benthem, M.G. Verbeek, B. Smit, Angew. Chem. Int. Ed. Engl. 41 (2002) 2500.

[9] R. Krishna, B. Smit, S. Calero, Chem. Soc. Rev. 31 (2002) 185.

[10] H. Stach, H. Thamm, J. Jänchen, K. Fiedler, W. Schirmer, in: D. Olson, A. Bisio (Eds.), New Developments in Zeolite Science and Technology, Proc. of the 6th Int. Zeolite Conference, Butterworth, Guildford, UK, 1984, p. 225.

[11] T.J.H. Vlugt, R. Krishna, B. Smit, J. Phys. Chem. B 103 (1999) 1102.

[12] R. Krishna, B. Smit, T.J.H. Vlugt, J. Phys. Chem. A 102 (1998) 7727.
[13] B. Smit, T.L.M. Maesen, Nature 374 (1995) 42.

[14] B. Smit, J. Phys. Chem. 99 (1995) 5597.

[15] W.J.M. van Well, X. Cottin, B. Smit, J.H.C. van Hooff, R.A. van Santen, J. Phys. Chem. B 102 (1998) 3952.

[16] A.H. Fuchs, A.K. Cheetham, J. Phys. Chem. B 105 (2001) 7375.

[17] M.D. Macedonia, E.J. Maginn, Fluid Phase Equilibria 160 (1999) 19.

[18] L.A. Clark, R.Q. Snurr, Chem. Phys. Lett. 308 (1999) 155.

[19] A. Gupta, L.A. Clark, R.Q. Snurr, Langmuir 16 (2000) 3910.

[20] R.L. June, A.T. Bell, D.N. Theodorou, J. Phys. Chem. 94 (1990) 1508.

[21] R.L. June, A.T. Bell, D.N. Theodorou, J. Phys. Chem. 96 (1992) 1051.

[22] E.J. Maginn, A.T. Bell, D.N. Theodorou, J. Phys. Chem. 99 (1995) 2057.

[23] R.C. Runnebaum, E.J. Maginn, J. Phys. Chem. 101 (1997) 6394.

[24] D. Frenkel, B. Smit, Understanding molecular simulations: from algorithms to applications, second ed., Academic Press, San Diego, 2002.

[25] M.G. Martin, J.I. Siepmann, J. Phys. Chem. B 102 (1998) 2569.

[26] A.G. Bezus, A.V. Kiselev, A.A. Lopatkin, P.Q. Du, J. Chem. Soc., Faraday Trans. II 74 (1978) 367.

[27] Cerius $^{2}$ v4.2: Molecular modelling software for materials research, Molecular Simulation, Inc., Burlington, MA, USA and Cambridge, UK.

[28] S. Savitz, F. Siperstein, R.J. Gorte, A.L. Myers, J. Phys. Chem. B 102 (1998) 6865.

[29] F. Eder, J.A. Lercher, J. Phys. Chem. B 101 (1997) 1273.

[30] J.A. Hampson, L.V.C. Rees, in: T. Hattori, T. Yashima (Eds.), Zeolites and Microporous Crystals, Studies in Surface Science and Catalysis, vol. 83, Elsevier, Amsterdam, 1994, p. 197.

[31] F. Eder, J.A. Lercher, Zeolites 18 (1997) 75.

[32] W.J.M. van Well, X. Cottin, J.W. de Haan, R.A. Santen, B. Smit, Angew. Chem. Int. Ed. 37 (1998) 1081.

[33] W.J.M. van Well, X. Cottin, J.W. de Haan, B. Smit, G. Nivarthy, J.A. Lercher, J.H.C. van Hooff, R.A. van Santen, J. Phys. Chem. B 102 (1998) 3945.

[34] W.M. Meier, D.H. Olson, C. Baerlocher, Atlas of Zeolite Structure Types, fourth ed., Elsevier, Amsterdam, 1996.

[35] M.S. Sun, D.B. Shah, H.H. Xu, O. Talu, J. Phys. Chem. B 102 (1998) 1466.

[36] W. Zhu, J.M. van de Graaf, L.J.P. van den Broeke, F. Kapteijn, J.A. Moulijn, Ind. Eng. Chem. Res. 37 (1998) 1934.

[37] H.B. Abdul-Rehman, M.A. Hasanain, K.F. Loughlin, Ind. Eng. Chem. Res. 29 (1990) 1525. 